\title{
Os direitos humanos (re)conquistados no Brasil, desde a década de 1970*
}

\author{
Marcos Evandro Cardoso Santi ${ }^{1}$
}

\begin{abstract}
Resumo: Depois de situar as diferentes categorias teóricas de direitos humanos e dos direitos de cidadania, o ensaio narra e analisa as lutas de reconquista, a partir dos anos 1970, de um regime democrático e dos direitos a ele associados. Nada obstante a sociedade brasileira haver alcançado uma Constituição progressista ao conceber o elenco de direitos civis, políticos, sociais e difusos, as garantias de exercício desses direitos ainda estão sendo construídas desde então. Assim, o ensaio analisa a importância dos direitos civis e políticos recuperados nos anos 1970-80 e aborda ainda a recuperação da estabilidade monetária, nos anos 1990, como elemento essencial para que o País avançasse na direção de melhorias no plano dos direitos sociais e difusos. Por fim, são abordados os limites que a realidade socioeconômica e cultural impõe para que os direitos humanos sejam assegurados de forma mais ampla e permanentes para os brasileiros.

Palavras chave: direitos humanos; Constituição; democracia.
\end{abstract}

\begin{abstract}
After situating different theoretical categories of citizenship and human rights within the context, the essay describes and analyzes the struggle for re-attainment of a democratic regime and its resulting rights, since 1970. Despite the fact that Brazilian society conquered a progressive Constitution, which set out a broad list of civil, political, social and diffuse rights, the implementation of such rights is yet being built since then. Therefore, the essay analyzes the importance of civil and political rights regained in the 70's and 80's. It also addresses the regaining of financial stability in the 90's as the primary element responsible for the country's efforts toward enhancements in the field of social and diffuse rights. Finally, the essay addresses the constraints, imposed by social, economic and cultural reality, which represent a barrier to the guarantee that human rights are assured to all Brazilian on a permanent basis.
\end{abstract}

Keywords: human rights; Constitution; democracy.

\section{Introdução}

\footnotetext{
* Artigo submetido em 30 de Abril de 2013, e aprovado em 15 de Maio de 2012.

${ }^{1}$ Mestre em História Social pela UnB (2012); bacharel em Direito (1992) e em Economia (1985), ambos pela UnB. Consultor Legislativo do Senado Federal na área de Direito Constitucional. Ensaio apresentado na disciplina "Tópicos Especiais em História Cultural" do Programa de Pós-Graduação em História da Universidade de Brasília (UnB), ministrada pelas Prof ${ }^{\mathrm{a}} \mathrm{s}$. Dra ${ }^{\mathrm{a}}$. Cléria Botelho da Costa e Lucília de Almeida Neves Delgado, no primeiro semestre de 2010.
} 
A temática dos direitos humanos no Brasil ganhou uma dimensão especial a partir dos anos 1970, quando a luta dos brasileiros pela redemocratização política do País esteve mais intimamente associada às denúncias -internas e externas- das mais brutais práticas de violação dos direitos humanos por parte do aparelho de repressão estatal, tais como assassinatos por motivação política, prisões políticas arbitrárias e disseminado emprego da tortura.

O regime político implantado em 1964 foi liderado por forças políticas que não hesitaram em lançar mão de políticas restritivas ou mesmo supressivas de direitos e liberdades dos cidadãos e de seus organismos coletivos. Desse modo, o País vivenciou uma grande restrição dos chamados direitos de primeira geração, fossem eles civis (relacionados ao exercício das liberdades individuais) ou políticos.

Sob a ótica dos direitos humanos, em breve síntese, no Brasil do início dos 1960, a luta pela ampliação e aprofundamento sobretudo de direitos sociais (necessários a um mínimo de bem-estar dos cidadãos) culminou em retrocessos não só quanto a esses, mas, também quanto aos direitos civis e políticos. E, para que essa nova realidade emergisse no plano dos direitos, o regime político foi modificado, substituindo-se uma ainda incipiente e frágil democracia por um regime autoritário.

Essa breve regressão histórica é necessária para melhor situarmos o ponto central deste pequeno ensaio: numa sociedade contemporânea, como a nossa, particularmente após o final da Segunda Guerra Mundial, a observância e a eficácia dos diferentes tipos de direitos humanos encontram-se muito conectadas com o regime político adotado por essa sociedade.

Esse raciocínio aparentemente é óbvio e permite uma hipótese imediata: assim como a introdução do regime político autoritário em 1964 resultou na supressão de direitos de liberdade, a posterior luta pela redemocratização do País transformou-se, simetricamente, em sinônimo da luta pela recuperação de elementares direitos e liberdades perdidos durante o período militar. As particularidades dessa (re)conquista dos direitos humanos e da democracia, desde a década de 1970, evidenciam, entretanto, que a trajetória histórica peculiar da redemocratização brasileira explica em grande parte os próprios impasses atualmente constatados para que os direitos humanos sejam mais efetivamente observados em nosso País. 


\section{Os direitos civis e políticos como características indispensáveis à democracia}

$\mathrm{Na}$ Introdução, referimo-nos à clássica sequência teórica dos direitos (sejam eles classificados como humanos, de cidadania (MARSHALL, 1967: 87) ou, simplesmente, direitos de um determinado ordenamento jurídico, stricto sensu), divididos entre os de primeira, segunda e terceira geração, ou mesmo quarta, para alguns autores mais recentemente.

Essa classificação é empregada no Direito, na História ou na Ciência Política, pois descreve categorias de direitos prevalecentes durante determinados períodos históricos, considerando-se como ponto de partida o século XVIII, influenciado pelos Iluministas, pelas Revoluções nas colônias norte-americanas e na França, com as suas correspondentes declarações de "direitos do homem" (HUNT, 2009: 113).

Datam exatamente do século XVIII -embora não se possa deixar de referir que a Inglaterra já caminhara para esse rumo ao final do século XVII-, nas regiões acima mencionadas (França, Estados Unidos da América e, também, a Inglaterra), as primeiras experiências de Estado Liberal, que teve o mérito de substituir o poder absoluto do monarca pelo poder dos que eram considerados povo (em geral, de acordo com regras ainda censitárias). O Estado Liberal, em suas origens, ficou marcado como o da ascensão dos direitos civis, especialmente os chamados direitos de liberdade (como o de ir e vir e o de expressão). Embora os direitos políticos também fizessem parte das primeiras declarações já mencionadas (EUA e França), sua aplicação era restringida por critérios censitários, somente se universalizando no século XIX (MARSHALL, 1967: 87). Mesmo assim, como os direitos políticos têm sido compreendidos como um produto secundário dos direitos civis, essas duas modalidades integram o que se rotulou "direitos de primeira geração".2

\footnotetext{
${ }^{2}$ Os direitos de segunda geração são os direitos de sociedade, como os direitos sociais, econômicos e culturais. Embora já existissem direitos sociais nos séculos XVII e XVIII, foi com o advento da Revolução Industrial que os movimentos dos trabalhadores passaram a reivindicar melhorias de condições de trabalho, saúde e educação, por exemplo. Embora o século XIX tivesse sido marcado por essas lutas dos trabalhadores, e por sua organização sindical, somente no século XX os direitos sociais passaram a ser reconhecidos universalmente. Também no século XX surgiram os chamados direitos de terceira geração, difusos, de solidariedade ou fraternidade, "que englobam o direito a um meio ambiente equilibrado, uma saudável qualidade de vida, ao progresso, à autodeterminação dos povos" (MORÃES, 2008: 31).
} 
O Estado Liberal logo passou a ser pactuado por meio de um importante instrumento político-jurídico, a constituição (em Direito, denomina-se "constitucionalismo" a esse movimento histórico de edição das primeiras Cartas Políticas de organização do Estado e de suas relações com a sociedade), destinada a assegurar a soberania do povo, elencando seus direitos e liberdades em relação ao Estado. Desde então, qualquer regime político democrático do mundo ocidental é assim considerado se, ao menos, assegurar os direitos de primeira geração.

Segundo Bobbio, essas liberdades e direitos da primeira geração são caracterizados por uma concepção individualista de sociedade, também aplicável à noção ocidental de democracia:

O individualismo é a base filosófica da democracia: uma cabeça, um voto. Como tal sempre se contrapôs (e sempre se contraporá) às concepções holísticas da sociedade e da história, qualquer que seja a procedência das mesmas, concepções que têm em comum o desprezo pela democracia, entendida como aquela forma de governo na qual todos são livres para tomar as decisões sobre o que lhes diz respeito, e têm o poder de fazê-lo. (BOBBIO, 1992: 61)

A ditadura implantada no Brasil, em 1964, investiu progressivamente contra as liberdades. Sob a chancela, inicialmente, de atos institucionais colocados acima da Constituição, e, depois, por meio de duas constituições ainda mais ditatoriais (a Emenda $\mathrm{n}^{\mathrm{o}} 1$, ou Carta de 1969, se insere no contexto em que se vivenciou maior violência institucional 1968/1972 [SILVA, 1990]), o Pais viu crescer as práticas de prisões ilegais, exílios políticos, cassações de mandatos e de direitos políticos, assassinatos por motivação política, fechamento de organizações sindicais e populares, censura aos meios de comunicação, limitação -quase supressão- da liberdade de organização partidária e redução ou supressão de mecanismos jurídicos de defesa dos cidadão, como o habeas corpus.

Apesar dessa dura realidade, o governo militar empenhou-se em divulgar um discurso supostamente liberal, ao longo de quase toda a trajetória do regime; esforçou-se para manter uma fachada de "Estado de Direito" - certamente um direito construído sem e/ou contra a participação popular, que somente ocorria em eleições a princípio com pequena margem de escolha. Fazia parte desse esforço de um discurso "liberal" ou "democrático", manter os três Poderes em funcionamento, possuir uma Carta constitucional e realizar eleições periódicas 
(de dois em dois anos), das quais só participavam duas agremiações partidárias, a situacionista Aliança Renovadora Nacional (ARENA) e o oposicionista Movimento Democrático Brasileiro (MDB).

Além de procurar manter essa fachada de "Estado de Direito", o regime militar conseguiu expressiva legitimidade especialmente no período do chamado "milagre econômico", fenômeno experimentado entre 1968/73 e caracterizado por taxas elevadas de crescimento econômico e razoável estabilidade monetária -em grande parte graças a financiamentos externos e endividamento interno-, o que permitiu a adoção de políticas estatais que possibilitaram a um número maior de brasileiros se beneficiar dos direitos sociais ou de segunda geração.

Houve políticas sociais, como o Fundo Rural, que ao beneficiar a população rural gerou importante contrapartida de apoio político à ARENA, e políticas gerais na economia que permitiram aos setores médios e populares das cidades experimentarem momentos de elevação do consumo de bens duráveis, como automóveis, televisores, geladeiras e vários outros tipos de eletrodomésticos.

\section{As liberdades democráticas: a bandeira dos direitos humanos e da redemocratização (Brasil dos anos 1970)}

Não obstante a redução de certas liberdades ou a supressão de outras (especialmente no período de recrudescimento da ditadura, 1968/72), os opositores ao regime militar, no parlamento, na agremiação partidária aceita, o MDB, e progressivamente também nas universidades, escolas, bairros e sindicatos, foram construindo mecanismos de participação, reconquistando, na prática, certas liberdades e, aos poucos, começando a construir um caminho de transição para uma futura redemocratização.

Até mesmo entre os militares o aumento da violência institucional no período entre 1968/72 havia provocado divergências, tanto que o Presidente escolhido para governar de 1974/79, Ernesto Geisel, integrava o chamado grupo "castelista", adepto de uma redução dos mecanismos e instrumentos autoritários de exercício do poder, diferentemente de seu antecessor, o linha-dura Emílio Garrastazu Médici (SKIDMORE, 1994b). 
Além disso, o final do governo Médici coincidiu com o fim do chamado "milagre econômico brasileiro", em virtude de mudanças nos rumos da economia mundial, que passou por forte crise no setor financeiro e elevação abrupta dos preços do petróleo em 1973, o que custou ao regime um impacto de legitimidade até então não experimentado, pois as condições econômicas tornaram-se, a partir de 1973, um fator de insatisfação para parte expressiva da sociedade e mais um importante argumento para os oposicionistas.

Essa insatisfação resultou, num primeiro momento, na surpreendente derrota eleitoral da ARENA, partido de sustentação do regime implantado em 1964: o MDB elegeu dezesseis Senadores das vinte e duas vagas em disputa e quarenta e quatro por cento dos membros da Câmara dos Deputados (FLEISCHER, 1988: 73).

As condições econômicas dos anos seguintes tornaram-se, aliás, crescente motivo de insatisfação popular: os índices menores de crescimento na segunda metade dos anos 1970 e, piores ainda, nos anos 1980, em contraste com as crescentes taxas inflacionárias, foram consistentes combustíveis para a luta oposicionista (SANTANA, 2007: 287; 295).

No quadro de crise econômica, a inflação aterrorizou o País até a metade da década de 1990, ao produzir perda de poder aquisitivo dos assalariados e também de setores da pequena burguesia. Por isso, a luta pela reposição salarial esteve na base da reconstrução de um combativo movimento sindical não somente dos operários, mas também de setores médios da sociedade, tendo-se como exemplo os professores, bancários e médicos.

Essas breves pinceladas têm o objetivo de assinalar os principais fatores econômicos, sociais e políticos que se combinaram nas transformações iniciadas nos anos 1970. Uma última característica que não pode ser ignorada se refere à mudança da política externa norteamericana. Se os militares tiveram ostensivo apoio dos Estados Unidos para promover o golpe (SKIDMORE, 2003a: 389-399), a política de Jimmy Carter, iniciada no final dos anos 1970, de criticar a violação dos direitos humanos nos países socialistas liderados pela União Soviética, repercutiu nas lutas dos que combatiam as ditaduras da América Latina, sabidamente praticantes da tortura e de outras formas brutais de violação dos direitos humanos.

Postos esses argumentos, e retomando a cronologia histórica, a derrota da ARENA em 1974, além de por si só representar um abalo na sustentação política do regime, passou a ameaçar a supremacia governista no Senado, que renovaria dois terços em 1978. Foi então 
que o governo lançou mão do chamado "Pacote de Abril de 1977", contendo mudanças nas regras eleitorais e na estrutura do Judiciário brasileiro e foi imposto mediante o fechamento do Congresso Nacional.

Contra o "Pacote de Abril", pela primeira vez desde as manifestações populares de 1968/69, segmentos populares -especialmente os estudantes universitários- conseguiram retomar as manifestações de rua, de especial simbologia na luta oposicionista por liberdades.

As reações ao "Pacote de Abril' tiveram o condão de intensificar a aliança entre a oposição oficial -MDB- e os setores populares em torno de uma bandeira que bem resumia a luta pela redemocratização e pelos direitos humanos de primeira geração: liberdades democráticas. Esse conceito, um tanto amplo, agregava satisfatoriamente os desejos de recuperação das liberdades básicas, como o direito de ir e vir, a liberdade de expressão e de organização, quanto o anseio maior de transformar o regime político.

Há que se esclarecer, todavia, que embora a bandeira das liberdades democráticas tivesse praticamente unificado e uniformizado a luta central das oposições, as forças sociais e políticas de oposição -sobretudo com a crise do "milagre econômico"- retomaram com vigor a luta por direitos sociais. O maior exemplo disso foi a reorganização do movimento sindical no ABC paulista -e também em importantes capitais estaduais- que, ignorando a legislação autoritária, recuperou na prática, a partir de 1978, o direito de greve e obteve expressivas vitórias de reposição salarial e de melhorias nas condições de trabalho.

Ainda em 1978, as primeiras invasões a latifúndios sob litígio judicial (Fazenda Anoni, no Rio Grande do Sul, por exemplo) lançaram as sementes para a organização dos trabalhadores rurais, depois consolidada no Movimento dos Trabalhadores Rurais sem Terra MST.

Também foi na década de 1970 que a grande massa de moradores da periferia das maiores cidades brasileiras construiu importantes organizações de moradores para reivindicar melhores condições de moradia, como rede elétrica, sanitária e pavimentação.

\section{A combinação entre os direitos humanos reivindicados: a caminho da redemocratização e da Assembleia Constituinte}

Tomando-se por base esse sucinto relato exposto até aqui, a luta pela redemocratização não pode ser explicada simplesmente como uma luta pela recuperação de 
direitos políticos e civis restringidos ou suprimidos pelo regime pós-1964. A luta pela redemocratização foi uma combinação de lutas pela conquista do conjunto clássico de direitos, a saber, civis, políticos e sociais (MARSHALL, 1967: 87).

$\mathrm{Na}$ conjugação das lutas pelos direitos humanos, a sociedade brasileira, no final da década de 1970 e durante a década de 1980 obteve muito mais resultados positivos no terreno dos direitos civis e políticos do que no campo dos direitos sociais. A crise econômica de 1973, seguida pela crise do sistema financeiro internacional em 1979, o pedido de ajuda brasileiro ao Fundo Monetário Internacional (FMI) logo após o pleito de 1982, a inflação, as baixas taxas de crescimento, o endividamento público e o endividamento externo são todos elementos de um mesmo quadro: a economia brasileira em crise desgastou o regime militar, mas não permitiu que os brasileiros obtivessem grandes melhorias em termos de direitos sociais.

Ao lado dos importantes passos já assinalados de reorganização dos movimentos sociais (passeatas estudantis a partir de 1977, com reorganização das entidades representativas; reorganização do movimento sindical, com maior autonomia em relação ao Estado; MST), algumas conquistas foram se efetuando no plano da recuperação dos direitos civis e políticos, como o fim do AI-5 em 1979; também em 1979, a conquista da primeira etapa da anistia, que significou a volta ao País de centenas de exilados; a ampliação da liberdade de organização partidária em 1980 (embora com propósitos de dividir as oposições); e a eleição direta para governadores estaduais em 1982, quando a oposição venceu em dez Estados, incluindo-se os maiores e mais importantes, como São Paulo, Rio de Janeiro e Minas Gerais (FLEISCHER, 1988).

A partir do cenário institucional construído nas urnas em 1982, o principal direito político ainda a ser resgatado era o de eleger diretamente o Presidente da República. Esse cenário institucional -com a oposição ocupando espaços estaduais e municipais de poder-, a recuperação de liberdades e a reorganização de parcelas importantes da sociedade compõem o quadro para explicar a grande campanha pelas "Diretas-Já", no ano de 1984, quando foi votada no Congresso Nacional a Proposta de Emenda Constitucional "Dante de Oliveira”.

Embora o fracasso daquela tentativa, a grande articulação política e a mobilização popular que se criaram em torno dela, bem como as divisões do regime em torno da candidatura situacionista à sucessão do Presidente João Figueiredo, fizeram com que após a 
derrota da "Emenda Dante", as oposições -à exceção do Partido dos Trabalhadores, que se posicionou contrariamente à eleição direta do futuro Presidente- conseguissem redimensionar suas forças para disputar a eleição indireta no colégio eleitoral.

Lançado pelo Partido do Movimento Democrático Brasileiro (PMDB) e apoiado pela Frente Liberal, dissidência criada no Partido Democrático-Social (PDS), sucessor da ARENA, Tancredo Neves elegeu-se Presidente do Brasil, tendo como Vice, José Sarney, indicado pela Frente Liberal, mas filiado ao PMDB.

A candidatura de Tancredo, mesmo tratando-se de uma eleição indireta, obteve amplo apoio dos partidos oposicionistas, dos segmentos organizados da sociedade e da própria população, porque representaria o fim do ciclo militar no poder. Além disso, agregando um conjunto tão amplo de forças políticas, Tancredo estava comprometido em consolidar as conquistas democráticas, ampliar a redemocratização do País e adotar políticas de redução das desigualdades sociais. Para tanto, além da atuação como governante, Tancredo comprometera-se a convocar uma Assembleia Constituinte democrática, que restabelecesse amplamente as liberdades e os direitos civis e políticos e caminhasse no sentido da redução das desigualdades sociais.

A vitória de Tancredo significou uma transição sem rupturas, sem maiores traumas com os militares. Diferentemente do que ocorreu na maior parte dos países latino-americanos, nos quais a queda das ditaduras de alguma forma envolveu processos violentos, no Brasil a adesão à candidatura de Tancredo por parte de integrantes do PDS (especialmente de políticos ligados a Ernesto Geisel) foi interpretada como uma chancela de setores militares que não aceitaram Paulo Maluf como candidato situacionista.

Não coube a Tancredo, todavia, a condução do processo, em virtude de doença que resultou em seu falecimento no simbólico 21 de abril de 1985. A José Sarney (em articulação com o presidente nacional do PMDB, Deputado Ulysses Guimarães), que assumira no dia 15 de março, caberia manter os compromissos, especialmente a (re)constitucionalização do País.

E o passo seguinte no processo de redemocratização e reconquista de direitos seria um daqueles raros momentos na história política de uma nação, um momento de (re)fundação, na linguagem jurídica, em que, necessariamente, o sucesso depende da interação entre a sociedade e seus representantes, qual seja, o momento constituinte, de elaboração de uma

\section{Em Tempo de Histórias}

Publicação do Programa de Pós-Graduação em História da Universidade de Brasília (PPGHIS/UnB) $\mathrm{N}^{\circ}$. 22, Brasília, Jan. - jul. 2013. ISSN 2316-1191 
nova Constituição Política que viesse consolidar, no plano jurídico, o processo de redemocratização alcançado com o fim do regime militar.

Assim, cumprindo os compromissos de campanha de Tancredo, José Sarney, o Presidente empossado, encaminhou ao Congresso a proposta de convocação de uma Assembleia Nacional Constituinte, que resultou na Emenda Constitucional no 25, de 1985. Não foi, como muitos setores da sociedade reivindicavam, uma Constituinte livre e soberana, mas, tão-somente, um Congresso Nacional que, eleito em 1986, exerceu o papel de Assembleia Constituinte. Aos eleitos em 1986 ainda somaram-se como constituintes os senadores eleitos em 1982, que continuavam como congressistas.

A eleição para a Constituinte foi prejudicada sob relevantes aspectos: em primeiro lugar, a influência do sucesso efêmero do Plano Cruzado, que fez com que o PMDB fosse ampla e artificialmente vitorioso -o plano, entretanto, ruiu logo após as eleições, desnudando a sua face eleitoreira; por outro lado, as eleições para governadores foram colocadas no centro do debate político, dando-se importância secundária ao caráter constituinte do novo Congresso.

Não obstante esses graves problemas de origem, de interferência na expressão da vontade popular, o processo constituinte surpreendeu pela significativa atuação da sociedade, particularmente de seus setores mais organizados, o que acabou por produzir um texto mais progressista e avançado do que fazia supor a composição do Congresso.

A atuação dos setores populares organizados -com segmentos que levantavam os mais variados tipos de bandeiras, desde a ampla recuperação dos direitos de liberdade até o fim dos diversos preconceitos às minorias-, particularmente dos sindicatos de trabalhadores, que já contavam com organismos técnico-políticos de grande valia como o Departamento Intersindical de Estudos Estatísticos e Sócio-Econômicos (DIEESE) e o Departamento Intersindical de Assessoria Parlamentar (DIAP), possibilitou que o novo texto constitucional, além de consumar a reconquista dos direitos civis e políticos e, sob certos aspectos, a ampliação deles, significasse também a conquista de algumas melhorias em termos de direitos sociais, como a redução da jornada máxima de trabalho para 44 horas semanais, a ampliação da licença-gestante para cento e vinte dias, o salário-desemprego, o adicional de férias, o aumento dos adicionais de hora extra, entre outros. 
Em apertada síntese, o texto da Constituição de 1988 incorporou uma das mais modernas declarações de direitos do mundo ocidental, aproveitando-se sobretudo das experiências constitucionais de Portugal e da Espanha, nos anos 1970.

A progressista declaração de direitos civis, políticos e sociais, bem como a previsão de mais eficazes instrumentos de garantia judicial e administrativa ao exercício desses direitos e liberdades, foi inspirada numa concepção não somente democrática, mas democrática pluralista, em que as minorias devem ser rigorosamente respeitadas e incluídas nos processos decisórios estatais.

Parte importante da Constituição brasileira foi destinada a consagrar entre nós, também, os chamados "direitos de terceira geração", caracterizados muito mais pelo interesse coletivo (em geral, também difuso) do que individual, a exemplo do direito a um meio ambiente saudável ou de defesa dos consumidores em geral.

À própria concepção individualista dos chamados direitos de primeira e segunda gerações foram, em vários aspectos, adicionadas formas coletivas de tratamento desses direitos, existindo agora uma gama expressiva de mecanismos judiciais que permitem a postulação coletiva em juízo, ou ainda por meio do Ministério Público.

Outro aspecto que simboliza a valorização dos direitos no texto de 1988 é o deslocamento da declaração para o título II, antes, portanto, dos títulos destinados à organização do Poder Público (Estado e Federação). Tal providência não foi casual; pensouse, justamente, na valorização do indivíduo e da sociedade perante o Estado, o que culminou, inclusive, com a definição, atribuída a Ulysses Guimarães, de que se tratava de uma "Constituição-Cidadã".

Com todos esses avanços no plano institucional, a Assembléia Constituinte configurou um exemplo de como a participação dos setores populares pode interferir nas deliberações dos representantes. A articulação, durante os trabalhos da Constituinte, do chamado "Centrão", bloco suprapartidário majoritário que agregava os setores mais conservadores da Constituinte e do qual participavam os principais líderes do governo Sarney, foi motivada para produzir um texto constitucional conservador e pouco receptivo aos anseios populares. A reação dos setores de esquerda, centro-esquerda e até mesmo de centro da Constituinte, respaldados pelas reivindicações dos movimentos sociais organizados, conseguiu ao menos equilibrar o jogo de forças e assegurar uma Constituição democrática. 
Desse modo, explica-se por que a consolidação do processo democrático, com a Constituição de 1988, significou a construção não de um mero Estado de Direito, mas, sim, de um verdadeiro e adjetivado Estado Democrático de Direito, com as repercussões que isso significa em termos do conjunto de direitos da cidadania, inclusive indo além da clássica divisão dos direitos, conforme já assinalado, uma vez que os chamados "direitos difusos" ou "de solidariedade" passaram a ser expressos no texto constitucional vigente, assim como as formas coletivas de reivindicação judicial, particularmente no que diz respeito às competências do Ministério Público para atuar em nome da sociedade.

Após a Constituinte, para completar o ciclo de transição para a democracia, num País de tradição presidencialista, faltava, ainda, a eleição direta do Presidente da República. Foi o que ocorreu em 1989, num pleito isolado, em que Fernando Collor de Mello, pelo pequeno Partido da Reconstrução Nacional (PRN), derrotou, no segundo turno, o candidato do PT, Luiz Inácio (Lula) da Silva.

\section{Da declaração constitucional dos direitos à sua eficácia: um longo caminho}

Os avanços consagrados na declaração de direitos do título II da Constituição Brasileira -acrescidos de vários outros direitos previstos ao longo do texto constitucional, particularmente no título VIII, Da Ordem Social- e na redemocratização das instituições políticas foram conquistas essenciais para consolidar a superação do período ditatorial.

Todavia, os postulados de redução das desigualdades regionais e sociais no Brasil que para muitos autores definem a face substantiva de uma democracia (em contraponto a face adjetiva, formal, processual ou procedimental)- só mais recentemente puderam apresentar resultados mais perceptíveis. A prolongada crise econômica dos anos 1970 não arrefeceu antes das mudanças econômicas do final da primeira metade da década de 1995, que possibilitaram -depois de diversas e variadas tentativas- enfrentar satisfatoriamente o problema da instabilidade monetária (inflação).

Essa diferença de facilidades/dificuldades na implementação das diferentes modalidades de direitos no Brasil não é uma particularidade de nosso País. Também nesse tema, a lição de Bobbio é esclarecedora: 
Essa universalidade (ou indistinção, ou não-discriminação) na atribuição e no eventual gozo dos direitos de liberdade não vale para os direitos sociais, e nem mesmo para os direitos políticos, diante dos quais os indivíduos são iguais só genericamente, mas não especificamente. [...] Só de modo genérico e retórico se pode afirmar que todos são iguais com relação aos três direitos sociais fundamentais (ao trabalho, à instrução e à saúde). (BOBBIO 1992: 71) (Grifos meus)

O que parece mais acentuado no caso brasileiro, no período estudado -e que vale também para muitos países da América Latina ou em fase "intermediária" de desenvolvimento capitalista-, é que as enormes desigualdades sociais, produzidas ao longo de séculos de história, somadas a situações de crise econômica mais recentes, aumentam ainda mais os obstáculos para a eficácia dos direitos sociais. Exemplo disso foi que, ao longo de décadas de crise econômica, houve um sucateamento dos órgãos e serviços públicos voltados para a satisfação dos direitos sociais: é o caso das escolas públicas, hospitais e ambulatórios ou de planos de previdência social.

A política econômica de controle da inflação adotada no final do governo Itamar Franco e no governo Fernando Henrique Cardoso (FHC) trouxe um equilíbrio monetário há muito desejado por autoridades, empresários e trabalhadores, que, no médio e longo prazo vieram a possibilitar melhores condições para o Estado adotar políticas públicas nas áreas sociais.

Por outro lado, a política de FHC de taxas de inflação apresentou um lado recessivo (as taxas de juros continuaram altas), o que fez crescer os índices de desemprego em seu segundo mandato presidencial e dificultou a expansão das atividades econômicas, como um todo. Antes disso, também, o governo FHC propôs e o Congresso aprovou, em 1998, uma Reforma da Previdência, tornando mais rígidos os critérios para a concessão de aposentadoria e pensão.

Não obstante esses problemas, já no governo FHC e nos governos de muitas unidades da federação, os anos 1990 marcaram o início efetivo de políticas públicas voltadas para a garantia de renda mínima aos segmentos mais miseráveis da população.

Nos dois mandatos presidenciais de Luiz Inácio (Lula) da Silva, apontam os índices governamentais para uma ampla expansão dos beneficiários dos programas sociais que concedem uma renda mínima. Além disso, foi consolidada na década 2001-10 uma política de 
recomposição do poder aquisitivo do salário mínimo. Essas duas políticas públicas têm sido as principais responsáveis pela redução dos níveis de miséria no Brasil.

Por outro lado, superada a fase inflacionária, o País também experimentou uma década de crescimento econômico, com taxas superiores à média mundial. Essa recuperação econômica atrai investimentos e consequentemente gera mais empregos, ampliando as possibilidades de atendimento de direitos sociais a parcelas importantes dos brasileiros.

Essas modificações no panorama social do País justificam os índices expressivos de popularidade do presidente Lula, que conseguiu transferir apoio à candidatura de Dilma Rousseff, eleita a primeira mulher a presidir o País.

\section{A Declaração Universal dos Direitos Humanos de 1948 e um balanço dos direitos humanos no Brasil}

Embora a Declaração Universal dos Direitos Humanos de 1948 balize políticas globais - por ser o documento ainda em vigor sobre o tema para todos os países que integram a Organização das Nações Unidas (ONU)-, o Brasil, por meio de seu ordenamento jurídico interno, conseguiu se colocar ao lado das mais avançadas declarações nacionais, em termos de direitos humanos. A Constituição de 1988 contém um dos mais modernos elencos de direitos constitucionalizados, bem como instrumentos institucionais destinados a garanti-los, embora a Defensoria Pública ainda precise ser uma instituição muito mais bem estruturada do que hoje, a fim de se colocar em condições semelhantes aos demais órgãos que atuam na esfera judicial.

A nossa realidade sócio-econômica e, também, a política, todavia, ainda demonstram grandes dificuldades para que o efetivo exercício dos direitos humanos seja uma realidade para grande parte dos brasileiros.

No final do item anterior, analisamos sucintamente as dificuldades que as sucessivas e prolongadas crises econômicas produziram e que impedem o Estado de atender a contento às demandas sociais em áreas estratégicas, como educação, saúde, saneamento básico, urbanização ou segurança pública.

Uma década de recuperação econômica e de políticas de melhoria desses setores -e que não foram acompanhadas de mudanças mais estruturais para a redução das desigualdades-, assim como de elevação da renda nas faixas de maior pobreza, é muito pouco

\section{Em Tempo de Histórias}

Publicação do Programa de Pós-Graduação em História da Universidade de Brasília (PPGHIS/UnB) $\mathrm{N}^{\circ}$. 22, Brasília, Jan. - jul. 2013. ISSN 2316-1191 
tempo para mudar mais expressivamente a nossa realidade, se consideradas as imensas necessidades e carências de um País com mais de quinhentos anos de muitas desigualdades sociais e regionais.

Além isso, não obstante a recuperação das liberdades, não podemos deixar de mencionar enormes dificuldades que enfrentamos também no campo político, como o hipertrofiado Poder Executivo, uma relação federativa que concentra os poderes e os recursos públicos na União, recuo da presença popular na cena política, organizações partidárias pouco representativas e um sistema eleitoral -que raros países adotam-que personaliza as disputas eleitorais e inibe a discussão das ideias e propostas.

Assim, mesmo se confrontarmos a realidade brasileira com a Declaração Universal dos Direitos Humanos de 1948 (PRESIDÊNCIA, 2008: 11-13), bem mais singela que a contida em nossa Constituição, poderemos constatar que -em virtude da combinação desse quadro político ainda centralizador, da recuperação apenas incipiente da economia e as dificuldades sociais de grande parcela dos brasileiros- subsistem preocupantes violações dos direitos humanos, entre as quais as anotações a seguir representam apenas alguns exemplos:

1. os preconceitos - de raça, cor, religião, sexo, orientação sexual, naturalidade ou nacionalidade ou os decorrentes de deficiência física- não podem ser desconsiderados, a despeito de toda a legislação repressiva. Mudanças culturais ocorrem no longo prazo, e a legislação tem apenas um papel relativo no rumo das mudanças pretendidas;

2. a segurança das pessoas, especialmente nas periferias das grandes cidades, é uma das maiores preocupações da população dessas áreas -evidentemente, o problema de segurança pública não se limita somente às áreas indicadas. Além disso, o acirrado conflito entre policiais e criminosos ainda mantém a prática da tortura e dos maus tratos na pauta de muitas delegacias;

3. o trabalho escravo ou a ele assemelhado sempre foi uma prática recorrente em muitos latifúndios, sobretudo na região Norte, em áreas de floresta. A atuação dos fiscais do Ministério do Trabalho apenas comprova que tal prática não foi erradicada. E, atualmente, o País passa a apresentar esse mesmo tipo de problema especialmente na produção industrial que utiliza como mão de obra estrangeiros em situação irregular no País; 
4. o trabalho doméstico também ainda apresenta muitas situações semelhantes à do trabalho escravo, tendo em vista a não regulamentação de sua jornada de trabalho, nem a concessão de uma série de direitos já conquistados pelos demais trabalhadores;

5. o acesso ao Poder Judiciário não é possível a grande parte da população. A Defensoria Pública é o setor menos desenvolvido entre aqueles que operam com o Direito;

6. o direito de propriedade no Brasil é um dos principais elementos de desigualdade. Nas áreas urbanas, recentemente programas mais amplos para assegurar moradia demonstram que há um grande déficit habitacional nas camadas pobres. No campo, a reforma agrária nunca passou de um programa de assentamentos pontuais, atendendo parcela significativamente inferior ao número dos que se candidatam a trabalhar no campo.

7. além de apresentar níveis expressivos de desemprego, no Brasil muitos trabalhadores não tem sua situação reconhecida oficialmente (trabalho informal), o que se traduz em perda de direitos trabalhistas e previdenciários. Além disso, o salário mínimo, embora crescente em termos reais, não é suficiente para atender a todas as demandas de uma família, o que é a "porta de entrada" para o caminho ilegal do trabalho infantil;

8. a rede de saúde pública vem sofrendo um distanciamento em relação aos serviços particulares (mais próximos dos padrões dos países capitalistas desenvolvidos). O problema tornou-se ainda mais preocupante após o fim da cobrança da CPMF, cujos recursos eram em grande parte destinados à área de saúde;

9. na área de educação, até o ensino médio, ocorre também expressivo distanciamento entre os serviços públicos e privados. Além disso, o País permanece estagnado nas estatísticas internacionais a respeito da qualidade de ensino.

\section{A história não esclarecida}

As negociações para a superação do regime militar, iniciadas com a eleição de Tancredo Neves-José Sarney, em 1985, aparentemente teriam sido concluídas em 1999, com a promulgação da Emenda Constitucional no 23, que criou o Ministério da Defesa. 
Todavia, ao longo - e depois- desse período, tem sido evidente a influência dos militares para preservar longe de um controle político, ainda que exercido democraticamente, determinados aspectos, peculiaridades e fatos do regime militar e da própria continuidade da vida militar atual.

Essa relação com os militares reflete a face frágil de nossa democracia, conquistada com a participação popular, mas, sem dúvidas, também à base de acordos nos bastidores de Brasília.

Se isso, hoje, não mais representa uma ameaça de golpe ao regime democrático, significa, ao menos que os militares de hoje ainda têm muita resistência para tentar preservar o sigilo sobre os atos dos militares da ditadura.

Para superar esse quadro, porém, duas importantes medidas foram aprovadas recentemente, já no governo Dilma Rousseff: a edição da "Lei de acesso às informações" e a criação da "Comissão da Verdade".

Se o governo Lula conseguiu avançar muito na concessão de anistia aos punidos pelo regime autoritário, restabelecendo caso a caso (por meio da Comissão de Anistia do Ministério da Justiça) os direitos dos anistiados ou de seus familiares, o mesmo não se pode afirmar em relação ao direito à memória e à verdade. Os arquivos do período militar classificados como sigilosos somente agora começarão a ser abertos. Embora, contudo, especule-se que muitos dos arquivos mais importantes já foram eliminados. Certamente, contudo, ainda há receios políticos para que os fatos sejam esclarecidos.

A ausência de política de acesso durante muito tempo fez com que haja "processos em curso na Justiça reivindicando que o Estado abra seus arquivos e libere as informações para se promover a localização dos restos mortais dos desaparecidos e a identificação e responsabilização dos agentes que hajam cometido violência contra os direitos humanos durante o regime de exceção" (PRESIDÊNCIA, 2008: 192). São, entretanto, casos isolados, em que familiares ou amigos das vítimas não desistiram de procurar a verdade sobre essas pessoas. Mas a verdade e a memória, do ponto de vista institucional e que interessa ao conjunto da sociedade, ainda continuará na dependência da abertura desses documentos "sigilosos".

$\mathrm{Na}$ tentativa de encontrar um remédio constitucional que assegurasse o direito à verdade, os constituintes de 1987/8 criaram o habeas data, por meio do qual é possível o 
acesso a informações "constantes de registros ou bancos de dados de entidades governamentais ou de caráter público". Mais do que o acesso à informação, o habeas data é também um instrumento jurídico que permite a retificação dessas informações: obviamente os constituintes examinaram, neste ponto, a possibilidade de muitas informações terem sido produzidas erroneamente, com base em interesses políticos ou ideológicos, em prejuízo ao indivíduo investigado ou perseguido pelo regime.

As questões colocadas neste item servem para destacar que, além das dificuldades anteriormente assinaladas de eficácia dos direitos humanos -especialmente as que decorrem das históricas desigualdades entre os brasileiros-, a redemocratização somente agora criou os meios políticos necessários para que a História da ditadura seja devidamente esclarecida. A eficácia desses meios -a "Lei de acesso às informações" e a "Comissão da Verdade"- ainda passará por testes e por obstáculos, a exemplo das pessoas que atuaram na repressão política.

\section{Conclusões}

A nossa premissa, neste ensaio foi a de que a redemocratização do País foi o caminho coincidente com o da (re)conquista dos direitos humanos. Houve e tem havido uma simbiose progressiva entre recuperação dos direitos (civis, políticos, sociais, difusos) e a evolução democrática.

Dessa simbiose, podemos concluir, também, que a democracia não é uma questão ainda resolvida no Brasil. Ao lado das enormes dificuldades para que a economia continue a crescer e que as desigualdades sociais e regionais sejam reduzidas a níveis aceitáveis, ainda devemos ter os olhos bem abertos para a grande centralização do exercício do poder e a fraca organização política da sociedade.

Da década de 1970 aos nossos dias, os avanços, as (re)conquistas de direitos atingem efetivamente uma parcela ainda minoritária dos brasileiros. Para parte expressiva dos cidadãos, entretanto, especialmente os direitos sociais e os direitos civis que necessitem da atuação do Poder Judiciário ainda são insatisfatoriamente exercidos.

Em síntese, portanto, se a redemocratização faz-nos constatar progressos em todas as modalidades de direitos humanos, com políticas públicas que vão consolidando expectativas otimistas, faz-nos também constatar que em todos os campos analisados -político, econômico,

\section{Em Tempo de Histórias}

Publicação do Programa de Pós-Graduação em História da Universidade de Brasília (PPGHIS/UnB) $\mathrm{N}^{\circ}$. 22, Brasília, Jan. - jul. 2013. ISSN 2316-1191 
social, jurídico- o período transcorrido foi muito pequeno para a consolidação de uma cultura política amplamente democrática, de um lado, e, de outro, um desenvolvimento sócioeconômico compatível com as declarações (da ONU ou da Constituição) de direitos humanos.

\section{Referências}

BOBBIO, Norberto. A era dos direitos. Rio de Janeiro: Campus, 1992.

CARVALHO. José Murilo de. Cidadania no Brasil: o longo caminho. Rio de Janeiro: Civilização Brasileira, 2008.

FLEISCHER, David (Org.). Da distensão à abertura: as eleições de 1982. Brasília: Editora Universidade de Brasília, 1988.

MARSHAL, T. H. Cidadania, classe social e status. Rio de Janeiro: Zahar, 1967.

MORÃES, Alexandre de. Direito constitucional. São Paulo: Atlas, 2008.

PRESIDÊNCIA DA REPÚBLICA. Secretaria Especial dos Direitos Humanos. Brasil: direitos humanos, 2008. A realidade do país aos 60 anos da Declaração Universal. Brasília: SEDH, 2008.

SANTANA, Marco Aurélio. "Trabalhadores em movimento: o sindicalismo brasileiro nos anos 1980-1990" In FERREIRA, Jorge e DELGADO, Lucília de Almeida Neves. O Brasil Republicano - o tempo da ditadura, livro 4. Rio de Janeiro: Editora Civilização Brasileira, 2007, p. 283-313.

SANTOS, Wanderlei Guilherme. Cidadania e justiça: a política social na ordem jurídica. Rio de Janeiro: Campus, 1987.

SILVA, José Afonso da. Curso de direito constitucional positivo. São Paulo: Revista dos Tribunais, 1990.

SKIDMORE, Thomas. Brasil: de Getúlio Vargas a Castelo Branco, 1930-1964. Rio de Janeiro: Paz e Terra, 2003a. Brasil: de Castelo a Tancredo. Rio de Janeiro: Paz e Terra, 2003b. 